\title{
MUJERES JÓVENES Y EL ABORTO EN CHILE: REPRESENTACIONES POLARIZADAS.
}

\author{
LISSETTE JARA ${ }^{1}$ / CAMILA ROJAS ${ }^{2} /$ SOLEDAD MARTINEZ $^{3}$
}

\section{RESUMEN}

El artículo presenta una aproximación exploratoria a la representación social sobre aborto en un grupo de mujeres jóvenes estudiantes universitarias en la ciudad de Chillán, Chile. Su importancia central radica en que la investigación se realiza justo en un marco temporo-espacial caracterizado por el debate nacional sobre la despenalización del aborto en tres causales, el que ha tenido lugar no solo en el ámbito legislativo, sino que a nivel de toda la sociedad chilena. El estudio fue cualitativo y utilizó cuestionarios abiertos y grupos focales. Los resultados muestran que el grupo con el cual se trabajó, representa el aborto de un modo altamente iconizado, con un componente emotivo importante, marcadamente negativo y centrado en aspectos individuales más que colectivos. Lo anterior coincide con los discursos conservadores y opositores a la despenalización del aborto en Chile.

Palabras clave: Aborto, Representaciones sociales, Género.

\footnotetext{
${ }^{1}$ Licenciada en Psicología y Psicóloga de la Universidad del Bío-Bío (Chile), tesista asociada a GECIEQ, Universidad del Bio-Bio (Chile). Avenida Andrés Bello 720. Código Postal 3780000 , Chillan, Chile. Correo electrónico: lissette.jara.cardenas@hotmail.com

${ }^{2}$ Licenciada en Psicología y Psicóloga de la Universidad del Bío-Bío (Chile), tesista asociada a GECIEQ, Universidad del Bío-Bío. Avenida Andrés Bello 720. Código Postal 3780000, Chillan, Chile. Correo electrónico: camrojas@alumnos.ubiobio.cl

${ }_{3}$ Psicóloga de la Universidad de Concepción (Chile) y Magister de la Universidad de Southampton (Inglaterra), Investigadora de GECIEQ, Universidad del Bío-Bío. Avenida Andrés Bello 720. Código Postal 3780000, Chillan, Chile. Correo electrónico: cmartine@ubiobio.cl
} 


\section{YOUNG WOMEN AND ABORTION IN CHILE: POLARIZED REPRESENTATIONS}

\section{ABSTRACT}

The article presents an exploratory approach to the social representation of abortion in a group of young female university students in the city of Chillán, Chile. The research has particular relevance because it was carried out in the midst of the national debate about the decriminalization of abortion in three specific cases. This debate has not only involved political and legal actors, but the whole Chilean society. The study was qualitative and used open questionnaires and focus groups. Results show that the researched group represents abortion in a highly iconic way, with an important emotional component that was very negative in nature and centered on the individual more than collective aspects. These results are consistent with conservative discourses that oppose the decriminalization discourses of abortion in Chile.

Key Words: Abortion, Social representations, Gender.

\section{Introducción}

El presente artículo da a conocer un acercamiento a las representaciones sociales de aborto de un grupo de mujeres universitarias de la ciudad de Chillán. Para ello, se efectúa un repaso del estado actual sobre el aborto y se exponen algunos aspectos teóricos de las representaciones sociales desde el enfoque procesual, incorporando una mirada de género. Posteriormente se presentan los resultados y, finalmente, se da paso a una discusión sobre el tema.

La investigación tuvo como objetivo general analizar las representaciones sociales de la población mencionada con respecto al aborto. Para tal efecto, el estudio se orientó bajo la siguiente pregunta: ¿Cuáles son las representaciones sociales sobre el aborto de un grupo de mujeres estudiantes de la Universidad del Bío-Bío, sede Chillán? L objetivos específicos del estudio fueron la caracterización de las actitudes, la interpretación de significados y el conocimiento de las prácticas sociales cotidianas asociadas al aborto. Lo 
anterior fue abordado desde una perspectiva epistemológica constructivista social.

\subsection{Antecedentes contextuales}

América latina es una de las regiones que presenta mayores restricciones legales al aborto en el mundo, y dentro de ésta son Chile, El Salvador y Nicaragua los países cuyas restricciones llegan a todo evento (Dides, Benavente y Sáez, 2011). Dichas restricciones son atribuidas a los ideales conservadores y la fuerte influencia de las iglesias cristianas, como también a influencias económicas sobre las políticas públicas de los países (Dides, Benavente y Sáez, 2011). Pese a ello, diversos estudios de opinión pública en Latinoamérica muestran que existe una tendencia a estar a favor de la despenalización del aborto, sobre todo en situaciones particulares. Particularmente, en Chile, las mediciones realizadas desde hace unos años van mostrando esta tendencia. Una encuesta Nacional realizada en el año 2005 por la Corporación Humanas y la Universidad de Chile encontró que del total de encuestados/as, la mayoría de las mujeres (56\%) cree que abortar es una decisión de la mujer en cualquier caso, y lo justifican mayoritariamente como forma de proteger la salud de la madre (67\%), en caso de inviabilidad del feto $(58 \%)$ y en caso de violación (55\%); no así por razones económicas, opción rechazada por el 85\% de las mujeres (Corporación Humanas, 2005).

Otra encuesta realizada el año 2014 por el Centro de Estudios Públicos (CEP) respecto a la despenalización del aborto, muestra que la mayoría (77\%) refirió estar de acuerdo solo en los casos en que el feto fuese inviable; un $70 \%$ se mostró de acuerdo solo en casos de violación, y un $72 \%$ solamente en casos en que el embarazo pusiese en riesgo la vida de la madre (Centro de Estudios Públicos, 2014). Estos estudios muestran que la ley en discusión actual cuenta con un amplio apoyo ciudadano, no obstante, persisten en el debate las dudas respecto a si legislar o no. Esto puede tener que ver con la importancia que tienen los grupos conservadores chilenos en la concentración de medios de comunicación, e instituciones que actúan como instancias de difusión de estas temáticas: 
La alta concentración de los medios de comunicación dificultaría la existencia de visiones plurales sobre el tema en la sociedad. Pese a que existe cierta evidencia respecto del apoyo que expresa la sociedad latinoamericana sobre reformas moderadas en el tema del aborto (cuando la vida de la mujer está en peligro o cuando es producto de una violación), el resultado político tiende a no responder a aquella demanda ciudadana porque en el debate político existen actores más influyentes que mantienen el statu quo. (Dides, Benavente y Sáez, 2011:10)

Desde la perspectiva legal, hoy se discute en Chile la reinserción en el ordenamiento jurídico de la figura del aborto terapéutico, la cual fue eliminada en septiembre de 1989 del Código Sanitario de 1984. Este señalaba en su artículo 119: "Solo con fines terapéuticos se podrá interrumpir el embarazo. Para proceder a esta intervención se requerirá de la opinión documentada de dos médicos cirujanos" (p. 25). Según sectores conservadores, la Constitución actual consagra tanto el derecho a la vida y a la integridad física de las personas, como la protección del que está por nacer, en su artículo 19 n¹, por lo tanto, la vida está protegida no solo desde el nacimiento, sino desde la concepción (Besio, Chomalí, Neira y Vivanco, 2008). Actualmente, el Código Penal chileno castiga como delito el aborto cometido: Artículo $342 \mathrm{~N}^{\circ} 1$ por un tercero con violencia; $\mathrm{N}^{\circ} 2$ sin consentimiento de la mujer; $\mathrm{N}^{\circ} 3$ con consentimiento de la mujer; Artículo 343 lo castiga si es cometido preterintencional con violencia; Artículo 344 si fue cometido por la propia mujer por móviles no relevantes; inc. 2 o por motivos sentimentales; Artículo 345 si fue cometido por un profesional (Código Penal de Chile, 1874).

\subsection{Antecedentes teóricos: Género y Representaciones Sociales}

Tomando en consideración lo anterior, entendemos que es necesario comprender el debate sobre aborto desde una perspectiva de género, definido como "la construcción cultural de la diferencia sexual, y por ello un elemento constitutivo de las relaciones sociales y la organización social de esas relaciones" (Scott, 1996:289). El género fija formas de ser, hacer y pensar en sociedad y supone diferencias de poder entre diferentes categorías sociales, dentro de las cuales son centrales las de hombre y mujer. El contexto ideológico en el que el género es producido es el patriarcado (Blazquez, Flores 
y Ríos, 2012). Tal ideología considera a la masculinidad como el modelo hegemónico que separa a nivel social al hombre y la mujer (Schongut, 2012).

Al asignar a las mujeres un conjunto de características, comportamientos y roles "propios de su sexo", los hombres quedan obligados a prescindir de estos roles y a tensar al máximo sus diferencias. Así, el patriarcado distingue dos esferas de acción y producción simbólica totalmente separadas e independientes entre sí: una pública, reservada a los varones para el ejercicio de poder político, social, del saber, económico, entre otros; y una privada, reservada para las mujeres que asumen subordinadamente el rol de esposas y madres. Dicha distinción es aplicable solo a las mujeres, dado que los hombres recorren y gobiernan ambas esferas (Facio y Fríes, 2005). En el caso de nuestra investigación, este modelo de masculinidad ejerce un control sobre el cuerpo de la mujer al violar sus derechos sexuales y reproductivos, incluyendo su derecho a la libertad, a la salud y a la seguridad (Centro Legal para Derechos Reproductivos y Políticas Públicas, 1998).

El Género corresponde a una categoría relacional que tiene en cuenta la experiencia, la subjetividad y el saber concreto. Asimismo, la teoría de las representaciones sociales no separa al sujeto social y el saber concreto de su contexto, debido a que la construcción de ese saber está ligada a la subjetividad (Blazquez, Flores y Ríos, 2012). En relación con lo anterior, esta teoría señala que determinadas formas de pensamiento particulares a cada sexo se ligan con relaciones sociales específicas, lo que lleva a comprender la masculinidad y la feminidad como categorías actualizadas constantemente por regulaciones sociales específicas y relacionadas con los contextos en que se producen. Por lo tanto, masculinidad y feminidad pueden ser comprendidas, desde este paradigma, como construcciones sociocognitivas, distanciando su causalidad de las diferencias entre los sexos a nivel social (Flores, 2003). De acuerdo a West y Zimmerman (1999) "en la medida en que la sociedad está dividida en diferencias esenciales entre hombres y mujeres, y la colocación en una categoría sexual es relevante y además impuesta, el hacer género es inevitable" (p. 127). 
La representación social se entiende como un conocimiento del sentido común que incluye contenidos cognitivos, afectivos y simbólicos que tienen una función no solo en ciertas orientaciones de las conductas de las personas en su vida cotidiana, sino también en las formas de organización y comunicación que poseen tanto en sus relaciones interindividuales como entre los grupos sociales en que se desarrollan (Araya, 2002). Las representaciones sociales tienen cuatro funciones: 1) de comprensión, puesto que permiten pensar el mundo y sus relaciones, 2) de valoración, debido a que posibilitan calificar o enjuiciar hechos, 3) de comunicación, a partir de la cual las personas interactúan mediante la creación y recreación de las representaciones sociales, permitiendo la transmisión y difusión del conocimiento ingenuo y 4) de actuación, la cual está condicionada por las representaciones sociales (Sandoval, 1997).

En términos de estructura la representación social está compuesta por tres dimensiones (Moscovici, 1979) que dan idea del contenido y del sentido del objeto de representación:

a) Actitud: corresponde a la dimensión afectiva, la cual le otorga el carácter dinámico a la representación y orienta el comportamiento hacia el objeto.

b) Información: la información como dimensión es la suma de conocimientos que posee un grupo con respecto a un objeto social.

c) Campo de representación: remite a la idea de "modelo social", está referido al orden y jerarquía que toman los contenidos representacionales, que se organizan en una estructura funcional determinada (por ejemplo, la "Teoría del Núcleo Central").

Moscovici (1988), tomando en cuenta la heterogeneidad de los grupos, clasifica las representaciones sociales en tres tipos: 1) Representaciones hegemónicas, aquellas creencias socialmente compartidas, simbólicamente poderosas que se asumen como naturales y menos susceptibles de discusión social; 2) Representaciones emancipadas, aquellas que sostienen grupos sociales específicos, portadores de nuevas formas de pensamiento social; y 3) Representaciones polémicas, que son aquellas que surgen entre grupos que atraviesan por situaciones de conflicto o controversia social respecto a hechos 
$\mathrm{u}$ objetos sociales relevantes $\mathrm{y}$ ante los cuales se expresan formas de pensamiento divergentes. La representación polémica "implica variación individual basada en condiciones donde prevalecen conflictos intergrupales" (Breakwell, 2001: 275). En el escenario actual del debate sobre aborto, lo anterior nos hace pensar que estos tres tipos de representaciones sociales se encuentran vigentes.

Los contenidos de la representación social polémica tienden a socavar la validez universal construida por los contenidos hegemónicos, para hacer valer nuevos contenidos o excepciones de significación (Rodríguez y García, 2007). Esto concretamente en el caso de aborto se refleja en el surgimiento de discursos alternativos sobre el tema, los cuales lo consideran, por ejemplo, como un problema sanitario (Colegio de Matronas y Matrones de Chile, 2014), como un Derecho Humano (Centro Legal para Derechos Reproductivos y Políticas Públicas, 1998) o como un problema de clase (Colectiva Feminista Libertaria "Histeria Colectiva", 2014).

La relación que se establece entre una representación hegemónica y polémica, pasa por la posibilidad de transformación que tiene una representación. Tal transformación se produce cuando es sometida a discusión social, por la influencia del flujo de la historia y -sobre todo-, por las acciones de personas y grupos sociales que repercuten en las formas de concebir objetos sociales relevantes. Es entonces de esta manera como una representación puede dejar de ser hegemónica, para volverse emancipada o polémica (Rodríguez y García, 2007).

Abric (1993) señala que existen tres formas en la sociogénesis de las representaciones y que contribuyen a explicar el desarrollo histórico de éstas. La primera se manifiesta como una resistencia a la transformación, y se da cuando las nuevas prácticas sociales conflictivas son incorporadas a la estructura de las representaciones actuales y manejadas con sus propios recursos simbólicos (cambian solo los elementos periféricos). La segunda se revela como una transformación progresiva, y se da cuando los sucesos novedosos no afectan seriamente los elementos centrales de la representación, en este caso la transformación se expresa sin rupturas graves con la estructura 
pasada de las representaciones sociales, activándose paulatinamente prácticas sociales nuevas (el núcleo central se altera por la integración de nuevos elementos sin fragmentarse el sistema central de elementos). Por último, identifica la transformación total del núcleo central, la cual ocurre cuando las prácticas sociales se introducen en la vida social de los grupos y afectan gravemente el marco de referencia en el que se expresan las representaciones sociales, en este caso las personas se ven imposibilitadas para retomar las antiguas prácticas que les ayudarían a afrontar lo novedoso (los mecanismos de defensa se vuelven incapaces de cumplir su rol).

Las representaciones sociales se encuentran en constante movimiento y transformación. De acuerdo a Figueroa (2014), hay tres dinámicas de cambio posibles de una representación:

a) Lenta: se trata de un cambio paulatino de mentalidad colectiva en función de nuevas prácticas. En este proceso se integran nuevos elementos, sean informativos, afectivos y/o emocionales. Se introducen en las prácticas colectivas nuevas formas de interacción.

b) Progresiva: surge de la coexistencia entre referentes hegemónicos y polémicos; supone tensión y tiene efectos en el discurso y en la práctica. Las personas perciben lo nuevo como amenazante, pero lo van asimilando y le van encontrado un lugar.

c) Abrupta: implica un cambio violento en el sistema de interpretación de las personas por factores casi siempre externos a las mismas. Es usual que se dé a partir de movimientos sociales o catástrofes naturales.

Para ser parte del sentido común, un contenido pasa por diferentes procesos sociales y de significación personal. En el proceso de generación de las representaciones sociales se pueden aislar dos subprocesos que aportan a la construcción de un tipo de conocimiento compartido de la realidad cotidiana de los grupos: se trata de la objetivación y el anclaje. Ambos procesos se refieren a la elaboración y funcionamiento de una representación social. E proceso de objetivación permite que los contenidos se simplifiquen y se vuelvan concretos, para ser incorporados en el mundo psíquico y en la comunicación (Moscovici, 1976; Jodelet, 1986). Las personas asocian de forma 
automática la información o idea con la imagen, esta materialización de lo abstracto se expresa a través de tres fases (Jodelet, 1986):

a) Selección y descontextualización: selección de la información relevante para las personas. La selección actúa como un filtro que retiene los elementos significativos y rechaza otros por no ser pertinentes. La información seleccionada se separa del contexto particular en el que aparece el objeto de interés para las personas.

b) Formación de un "núcleo figurativo": se refiere al esquema por medio del cual se hace visible el concepto. Los diferentes componentes de una realidad social concreta son visualizados a través de sus elementos más significativos. Una estructura de imagen reproduce de manera visible un concepto, la cual permite comprenderlo.

c) Naturalización: la imagen formada se convierte en elemento de la realidad, referente para el concepto. Los elementos figurativos se transforman en elementos de intercambio "natural" (conocidos y empleados por todos/as) en las relaciones cotidianas.

El anclaje es un proceso que apunta a la implantación social de la representación y de su objeto, en donde lo social se refleja en el significado y su utilidad (Jodelet, 1986). Este proceso consiste en nombrar y clasificar el nuevo conocimiento (objeto representado) dentro del sistema de pensamiento preexistente. El anclaje favorece la complejización de la representación social, en tanto ésta va adquiriendo mayor sentido, puesto que transforma la ciencia en un saber útil para todos/as. En este proceso se manifiestan tres aspectos que posibilitan comprender el funcionamiento de la representación social (Aguirre, 2004):

a) Sistema de interpretación: se refiere al funcionamiento de la representación social como un sistema de interpretación. En este proceso se atribuye un valor de utilidad social a los contenidos de la realidad representada y se los jerarquiza confiriéndoles un determinado valor, el cual que está fuertemente influenciado por las condiciones sociales.

b) Significación: Está relacionada con la configuración de la representación social como un conjunto de elementos de la realidad derivados del sistema de 
valores producido y aceptado por la sociedad ("red de significaciones"). Así, todo pensamiento social de la persona solo podrá ser comprendido gracias al vínculo que establece con la red de significaciones pre-existente en la sociedad, permitiéndole al individuo hacer explícita su pertenencia a un determinado grupo cultural, es decir, un grupo expresa su identidad mediante el sentido que le da a la representación.

c) Función de integración: Hace referencia a la inserción de la representación social en sistemas de pensamiento ya existentes y que podrían estar aislados por contextos diferentes, dicho en otras palabras, los elementos novedosos son explicados desde pensamientos pre-existentes, clasificando lo nuevo dentro de lo familiar.

En síntesis, objetivación y anclaje corresponden a procesos que permiten explicar cómo funciona el pensamiento social, en donde lo cotidiano pasa a ser un elemento relevante al ser un insumo para el estudio de la representación social.

\section{Metodología}

Esta investigación asumió un enfoque procesual, el cual considera que para acceder al conocimiento de las representaciones sociales se ha de partir de un abordaje hermenéutico, concibiendo al ser humano como productor de sentidos, y enfatizando en el análisis de las producciones simbólicas, de los significados, del lenguaje, mediante los cuales las personas construimos el mundo en que vivimos (Banchs, 2000). Desde este enfoque, Spink (1994) señala que las representaciones sociales son concebidas como "la actividad de reinterpretación continua que emerge del proceso de elaboración de las representaciones en el espacio de interacción lo que constituye, en nuestro modo de ver, el real objeto de estudio de las representaciones sociales en la perspectiva psicosocial" (121).

Para la obtención de la información se realizaron dos cuestionarios abiertos, los cuales fueron aplicados a 30 mujeres de entre 18 y 26 años, estudiantes universitarias de las carreras de trabajo Social, Psicología, Nutrición y dietética y Fonoaudiología. Dicha población permitió una mayor representatividad y a partir de esto, el reconocimiento de patrones de 
pensamiento. El criterio de inclusión de la población seleccionada se fundamenta en la cercanía y fácil accesibilidad a la muestra, sumado a la consideración de ésta como población culta, susceptible de brindar aportes de manera fundamentada y ser posibles usuarias —más no únicas - en caso de que llegase a despenalizar el aborto. En total, se obtuvieron respuestas a 60 cuestionarios, los que estuvieron compuestos por 5 o 6 preguntas graduadas cada uno.

Las categorías abordadas en este artículo son las cogniciones y actitudes ligadas a la representación social. Las cogniciones son abordadas desde los conceptos más recurrentes en la definición e imagen del aborto y el anclaje social del concepto. Las actitudes incluyen el grado de acuerdo y las prescripciones que las participantes hacen a la sociedad respecto del aborto. A pesar de ser elementos contenidos por las representaciones sociales, esta última categoría ha sido separada de la primera solo con fines de análisis.

Las preguntas del primer cuestionario estuvieron orientadas a interpretar las cogniciones sobre el aborto. La primera y segunda pregunta permitieron conocer los procesos de objetivación y anclaje, respectivamente. La tercera pregunta estuvo orientada a conocer el anclaje social de la representación y la cuarta pregunta las narraciones que componen la representación de aborto. Por último, la quinta pregunta posibilitó conocer el proceso de naturalización detrás de la representación social.

Las preguntas del segundo cuestionario estuvieron orientadas a caracterizar las actitudes sobre el aborto, en esta línea, la primera y cuarta pregunta permitieron conocer y caracterizar las creencias que componen la representación social de aborto. La segunda y sexta pregunta estuvieron orientadas a interpretar los valores asociados al aborto. La tercera pregunta favoreció la caracterización de los patrones conductuales vinculados al mismo. Finalmente, la quinta pregunta estuvo enfocada a caracterizar las interacciones sociales asociadas al tema.

Las categorías de análisis mencionadas (cogniciones y actitudes) fueron elegidas debido a que forman parte de una representación social. Por otra parte, las subcategorías que se señalan en el siguiente apartado fueron 
generadas a partir la densidad de aparición de las respuestas en los cuestionarios abiertos, tanto por frecuencia como por densidad simbólica. Los resultados son presentados incluyendo trozos literales de los reportes con fines ilustrativos, los cuales se señalan entre comillas. Entre paréntesis se identifica el número de la informante a la que pertenece la cita.

\section{Resultados}

\subsection{Cogniciones}

Una cognición es prescriptiva y/o descriptiva. El aspecto prescriptor de una cognición es el lazo fundamental entre la cognición y las conductas que se consideran corresponderle (...) El aspecto descriptivo de una cognición es más habitual: efectivamente, los/as sujetos/as, sobre todo en el estudio de las representaciones sociales, utilizan principalmente términos descriptivos (Abric, 1994, p. 33).

La dimensión de la Información traslada el qué a la riqueza de los datos o explicaciones que las personas se forman sobre la realidad en sus relaciones cotidianas (Araya, 2002), no obstante, de acuerdo a la autora, hay que considerar que las pertenencias grupales influyen en la cantidad y la precisión de la información otorgada. El origen de esta es, de igual forma, un elemento a tener en cuenta, ya que la información que surge de un contacto directo con el objeto, y de las prácticas que una persona desarrolla en relación con él, posee características diferentes de las que presenta la información recogida a través de la comunicación social.

Atendiendo al proceso de objetivación, es posible incorporar a esta categoría el concepto de imagen. La imagen se la concibe como reflejo interno de una realidad externa, copia fiel en el espíritu de lo que se encuentra fuera de él, por lo tanto, es la reproducción pasiva de un dato inmediato. Estas imágenes son construcciones combinatorias, análogas a las experiencias visuales. Estas imágenes son una especie de "sensaciones mentales", impresiones que los objetos y las personas dejan en el cerebro. Al mismo tiempo, mantienen vivas las huellas del pasado, ocupan espacios de nuestra memoria para protegerlos contra el zarandeo del cambio y refuerzan el 
sentimiento de continuidad del entorno y de las experiencias individuales y colectivas. Siempre operan como un filtro y provienen de filtrar informaciones que la persona posee o ha recibido en vista del placer que busca o de la coherencia que necesita. Así, es posible observar que una imagen está determinada por fines y que su función principal es seleccionar lo que viene del interior pero sobre todo del exterior: "Las imágenes desempeñan el papel de una pantalla selectiva que sirve para recibir nuevos mensajes, y a menudo dirigen la percepción y la interpretación de estos entre los mensajes que no son completamente ignorados, rechazados o reprimidos" (Moscovici, 1979 p. 31).

En consideración de lo anterior, la imagen de aborto está descrita por tres entidades representadas: la mujer, la tecnología y el feto-bebé o agente abortado. La actoría de las mujeres está conectada con sentimientos principalmente negativos y, secundariamente, con el derecho a decidir sobre su propio cuerpo. Las tecnologías se encuentran vinculadas a instrumentos médicos y a profesionales de la salud, quienes realizan los procedimientos del aborto. Por último, la participación del feto-bebé se encuentra ligada directamente con la vida, en este sentido, las universitarias consideran que el agente abortado posee o es vida, la cual pierde una vez que la mujer tiene y/o realiza un aborto. Este agente abortado, entonces, se caracteriza por su relación con la muerte: aparece la imagen de un ser ensangrentado, desmembrado, mutilado y/o en partes y que se encuentra ubicado en espacios determinados que lo contienen, tales como una mano humana, frascos y el vientre materno.

Muerte: las representaciones remiten a la idea de un feto o bebé que está muerto o amenazado de muerte. La imagen de la muerte está reforzada por aspectos asociados, tales como la sangre o el desmembramiento del cuerpo del bebé o feto:

Fetos muertos, brazos de fetos y partes (105)

Algo inhumano quitar la vida a un ser puro y sin culpa (I17)

Feto-bebé: este componente es también muy recurrente en la representación y cumple la función de participante central, es decir, el feto o bebé está siempre presente como principal o único participante en la representación. 
Frecuentemente este se encuentra contenido en frascos, manos o vientre materno:

Se me viene a la mente la imagen de un feto ya extraído en las manos de una persona, con su cuerpo no formado totalmente (I21).

Cuerpo de un bebé destrozado y desmembrado por partes, lleno de sangre (I16).

Tecnología: aparece en los discursos como todo procedimiento médico realizado por un tercero sobre el cuerpo y además hace referencia a la utilización de instrumentos o aparataje médico utilizado para llevar a cabo los abortos:

Forma cruda sobre la visión de un feto desmembrado por causas del aparataje utilizado al momento de realizar dicho procedimiento (I23).

Sentimientos asociados: las respuestas en relación al aborto se encuentran en su mayoría teñidas por emocionalidad y sentimientos negativos:

Imagen impactante y fuerte, me causaría mucha tristeza y pena. (104).

Preocupación, desolación y tristeza (I19).

Mujer: actora secundaria dentro de la representación, ya sea porque aparece con menor frecuencia, como porque sus acciones están subordinadas al participante principal. Cabe señalar que la imagen de la mujer resulta polarizada, incluso dentro de una misma respuesta, ya que se ubica dentro del polo de victimaria cuando elige abortar, y a la vez de víctima, cuando es empujada a cometer aborto. Por otra parte, es posible también reconocer otra posición, mucho menos relevante en las respuestas, que tiene que ver con la mujer empoderada que decide sobre su cuerpo:

Mujer asesinando algo que es parte de sí, fruto de ella misma (I24).

"Mujer decidida, dispuesta a luchar por sus derechos, dispuesta a salvar su vida o a no dejarse pasar por un abusador (107).

Uno de los aspectos más relevantes en las respuestas es el que dice relación con la forma en que el acuerdo o desacuerdo con la práctica del aborto es modulado por ciertos factores condicionantes:

Decisión personal/autorrealización: la importancia del desarrollo personal de cada mujer mencionando como justificación para realizarse un aborto, subyace a esta idea que la llegada de un/a hijo/a no permite el desarrollo de las 
potencialidades de las mujeres:

De acuerdo a lo impuesto por el patriarcado, ser mujer se vincula con la maternidad, pero hoy en pleno siglo XXI, ser mujer se relaciona con la igualdad de oportunidades, jla capacidad de decidir y optar por lo que se considera correcto! (I15).

Motivos: se señala que deben existir fundamentaciones, situaciones o circunstancias específicas para que las mujeres puedan abortar:

Las mujeres que abortan no todas son malas, ellas tienen distintos motivos para serlo. Yo opino que nadie tiene derecho de quitar la vida a un ser inocente (104).

Las mujeres que abortan "puede" que quieren otro futuro o no ser capaz de llevar en su cuerpo a un ser humano que nace de un abuso o por obligación moral y legal (108).

Tres causales: este subcomponente se relaciona con otra razón en la que el aborto es justificado que se produzca. Se reconoce a la mujer en una posición vulnerable o de víctima. Hace alusión al estar padeciendo algún tipo de violencia, ya sea esta física, emocional o sexual. Además, se hace explícita alusión a las tres causales propuestas en el proyecto de Ley actualmente en discusión:

En el caso de violación, para la mujer debe ser muy cruel pensar y ver a su bebé, si es bajo las 3 causas de la ley, considero que no son malas madres (I01).

El aborto es decisión de cada una (solo en caso terapéutico y violación) y el estado no debe decidir (I27).

Creo que es un proceso difícil pero que debe tomarse en cuenta al momento de implementar las leyes, ya que en ocasiones puntuales se hace necesario recurrir al aborto. Al no contemplarse esta opción se vulneran los derechos de la madre (I16).

Mujer afectada física y emocionalmente: en esta subcategoría se agrupa un tipo de respuesta en las que se menciona que la decisión de abortar es entendida y justificada cuando la mujer se encuentra en situación de vulnerabilidad, especialmente del tipo física o emocional:

"Una madre que ha abortado por razones clínicas que le afectan psicológicamente o físicamente y le llevan a tomar esa decisión también se puede desempeñar de forma correcta en su rol" (I03). 
Adolescencia: dentro de esta subcategoría se justifica la decisión de la mujer que aborta si se encuentra en esta etapa del desarrollo, ya que se considera como una condición de vulnerabilidad:

Por ejemplo una adolescente que queda embarazada por temor, miedo, por no tener responsabilidad frente a lo que le diga su familia, puede que tome esa decisión de abortar (102).

Riesgo: se observa en esta subcategoría la idea de que las mujeres que se realizan abortos o las que se encuentran más predispuestas a realizarlos son aquellas de estrato social bajo, que llevan a cabo conductas de riesgo o las que se encuentran en situaciones de vulnerabilidad:

En clases sociales más bajas y vulnerables, adolescentes, drogadictas, personas que sufren de abuso sexual (I17).

Derecho a decidir de las mujeres: en relación a esta idea, es posible observar presencia de pensamientos que hacen alusión al poder de decisión de las mujeres con respecto a su propio cuerpo, y la ausencia de ideología política o religiosa que determine su actuar:

Mujer libre que pueda decidir, que tiene opciones a su alrededor y que es libre de elegir la que le parece correcta (I14).

Violencia: se incorpora esta concepción de violencia de la cual ha sido víctima la mujer, especialmente por parte de un hombre, haciendo alusión directa a abusos y/o golpes, o a la violencia de la que es víctima el agente abortado cuando la mujer decide concretar un aborto:

Grupo de mujeres que quizás han sido abusadas sexualmente y llevan el feto de un hombre maltratador (I12).

\subsubsection{Anclaje social}

Respecto de la percepción que las jóvenes tienen de los posicionamientos sociales presentes en la actualidad en Chile, aparece una clara polarización de las visiones:

A favor: con esta postura se asocia de forma directa a los grupos feministas o liberales, que apoyan o defienden la libertad de las mujeres sobre su cuerpo y el poder de decidir sobre éste:

Grupos más liberales y también feministas que están de acuerdo con que cada mujer tenga derecho a decidir acerca de su propio cuerpo (I12). 
En contra: se observa una asociación a grupos más conservadores o "cerrados de mente", según lo mencionan las participantes, con un posicionamiento negativo, sin excepciones, hacia el tema del aborto.

Las personas pro-vida, que no están a favor del aborto, ni siquiera en sus 3 causales (107).

Por el lado de la iglesia es malo, ya que dicen que no podemos quitarle la vida a un bebé en desarrollo (I30).

Transversalidad: muy minoritariamente no se realiza vinculación con algún grupo en particular y se reconoce una transversalidad social del tema:

No tengo «un» grupo, sino que considero que el aborto es transversal a cualquier grupo social por diferentes motivos, y no lo considero propio solo de un tipo de persona definida (I22).

\subsection{Actitudes}

La actitud corresponde al elemento afectivo, siendo la más frecuente de las tres dimensiones de las representaciones. Las personas se informan y representan un objeto exclusivamente después de haber tomado posición y en función de la posición tomada (Moscovici, 1979). De acuerdo a Van Dijk (1999), la actitud corresponde a conjuntos específicos, organizados, de creencias socialmente compartidas que varían dependiendo el grupo de pertenencia. Las actitudes se inscriben junto con las opiniones y las ideologías dentro de las creencias evaluativas, que se distinguen de las creencias fácticas en que éstas incluyen el conocimiento considerado verdadero o falso.

Martin y White (2005) proponen el "Modelo de la Valoración". Este modelo aborda la expresión de la actitud que da cuenta de sentimientos, creencias y valores en diversos contextos comunicativos. Alude a la expresión valorativa de la actitud hacia personas, acciones, eventos, procesos y productos (Alarcón, 2014). La valoración es entendida como la construcción discursiva de la actitud y de la postura intersubjetiva. Comprende tres dominios: actitud, compromiso y gradación. La actitud a su vez se subdivide en tres regiones a través de las cuales se puede manifestar: afecto, juicio y apreciación (Martin y White, 2005). 
La actitud tiene que ver con los sentimientos, incluyendo las reacciones emocionales, sentencias del comportamiento y la evaluación de las cosas. E afecto supone la expresión de los sentimientos positivos y negativos. El juicio tiene que ver con la evaluación del comportamiento en función de las normas sociales establecidas y aporta un sentido ético y moral de la conducta; y la apreciación, que implica la valoración estética de las cosas y los fenómenos naturales (Martin y White, 2005).

La gradación supone el grado de intensidad (fuerza) de los enunciados, permite "subir" y "bajar" el volumen de estos y determinar su alcance o foco. E Foco puede considerarse como la aplicación de las escalas de intensidad a categorías no susceptibles de gradación (Kaplan, 2004). Respecto del nivel actitudinal sobre el aborto, aparte de las emociones ligadas a su imagen, existen valoraciones ligadas a las discusiones sociales sobre el tema. De allí es posible reconocer gradientes actitudinales:

Acuerdo total: se entiende que la valoración del aborto pasa por la libertad de decisión de cada mujer sobre su cuerpo, sin obligaciones ni sanciones de ningún tipo:

Personalmente creo que el aborto es una decisión personal, es decir, si la mujer desea interrumpir su embarazo debería estar en completa libertad en realizarlo, puesto que es su cuerpo y no debería existir ningún tipo de sanción al respecto (I39).

Acuerdo condicional: el valor del aborto está mediatizado por el acuerdo con el proyecto de ley de despenalización del aborto bajo tres causales: violación, riesgo de vida de la mujer e inviabilidad fetal:

La opinión que me merece es que justifico al aborto bajo las tres causales que están en discusión (I30).

Desacuerdo condicional: grado de acuerdo caracterizado por una oposición hacia el aborto donde este es valóricamente visto como negativo, pero justificado en casos de escasa esperanza de vida del bebé y/o cuando las mujeres no tienen otra alternativa:

Soy neutral en este tema, no es algo que particularmente me agrade pero pienso en que existen casos en los que las mujeres no tiene otra opción. Para mí la situación más recurrente a esto debiese ser cuando el feto viene sin vida 
o no tiene posibilidades de vivir y de alguna forma se le obliga igual a la madre a llevarlo en su vientre (I23)

Desacuerdo: se observa un rechazo total hacia el aborto, puesto que es visto como una práctica negativa e irresponsable:

En mi opinión el aborto es algo malo, puesto que han de hacerse cargo de sus actos y seguir adelante con el embarazo, aunque para eso debamos sacrificar mucho (I29).

Posicionamiento indirecto: el valor del aborto se encuentra mediado por la exposición de una opinión que no manifiesta de forma directa una postura respecto al tema:

Es un tema complejo puesto que involucra la vida y la muerte por lo cual existen distintas opiniones, puntos de vista y valores (I21)

\subsubsection{Prescripciones a la sociedad}

Las jóvenes participantes, junto con posicionarse respecto de la sociedad, también recomiendan o valoran que la sociedad realice algunas acciones sobre el aborto:

Debatir: se valora la discusión formal y organizada caracterizada por la exposición de posturas y/u opiniones argumentalmente opuestas sobre el aborto.

Considero que en nuestro país debería abrirse un amplio debate, incorporando todas las visiones, pero debe realizarse un debate serio, con argumentos científicos y no tan orientado a lo valórico y religioso (I27).

Incrementar participación femenina: subcategoría que se caracteriza por encargar a las mujeres la decisión de legalizar sobre el aborto, entendiendo que son ellas las directamente implicadas en el tema:

Creo que debería haber mayor participación femenina en la toma de esta decisión de legalizar o no el aborto, pues es un tema que nos afecta mayormente a nosotras y por lo mismo somos nosotras las que debemos decidir (I22).

Concientizar: la movilización de la conciencia de manera liberadora al tema (sus relaciones, causas y efectos), propiciando la desalienación de las 
personas, afirmándose estas como personas reflexivas, conscientes y comprometidas en la construcción de esta realidad:

Crear conciencia y a la vez orientación, además de no generar un tabú respecto al tema (I30).

Educar: dan importancia de la visibilización y conocimiento sobre el tema con la finalidad de construir un debate informado:

El aborto creo que merece un gran valor, debe dejar de ser un tema tabú, debe ser informado y sobre todo educado y solo cuando se dé una verdadera educación podremos debatir y opinar de mejor manera (I20).

Legalizar/legislar con condiciones: grado de acuerdo caracterizado por un posicionamiento a favor de legalizar y/o legislar el aborto solo en situaciones determinadas:

Legalizarlo pero indagar e informarse bien sobre las condiciones específicas en que se permitiría. No creo que debería legalizarse el aborto libre para mujeres que no han sabido llevar responsablemente su sexualidad (caso de mayores de edad) (I14).

No legalizar/legislar: desacuerdo con respecto a la legalización/legislación sobre el aborto:

Para mí no debería legalizarse, aunque se sabe que se hará ilegalmente (I30).

\section{Discusión}

La representación social de aborto que posee el grupo de mujeres estudiantes universitarias participantes en este estudio es esencialmente tradicional o hegemónica (Moscovici, 1988). Se ubica en el núcleo de dicha representación lo que hemos venido en llamar agente abortado, pero siendo referido por las participantes de la investigación como "feto" o "bebé". La objetivación es el proceso que permite poner en imágenes las nociones abstractas (Jodelet, 1986), la imagen de aborto integrada por estas mujeres se caracteriza por ubicar al agente abortado en el núcleo de la representación social, el cual es el participante principal, presenta una fuerte intensidad, alta carga simbólica y se encuentra naturalizado, situando a la mujer en una actoría secundaria. En otros términos, el aborto se significa principalmente como la muerte de un ser en un estado de desarrollo que no corresponde con el estado en el que se encuentra en un aborto, como el que se debate en la legislación 
chilena.

Podemos interpretar que las narraciones que han construido las participantes sobre el aborto se relacionan con el nivel de contacto o cercanía que han mantenido con el tema. Se evidencia una construcción de significados sobre el aborto fuertemente influenciada por los discursos reproducidos a través de los medios de comunicación de masas, en donde la imagen presente en estas mujeres se asocia a un "bebé" o "feto" que presenta un cierto desarrollo biológico, idea que es reforzada por el apoyo visual presentado mientras se habla del tema, mostrando a mujeres con un importante desarrollo de su embarazo. Frente a este imaginario que se sugiere, el aborto es visto como un atentado a la vida, y esta cualidad se considera como inherente al agente abortado y se entiende como la interrupción de un proceso. Además, dicha muerte es descrita con una fuerte carga emocional, atribuyendo sentimientos al agente abortado y a la mujer que aborta. Al agente abortado se le atribuye el dolor y sufrimiento, e incluso se le otorga capacidad de comunicar ese sufrimiento. En tanto a la mujer se le asigna la vivencia de culpa, insensibilidad, crueldad e inhumanidad.

A nivel de imagen, lo que representan las participantes de la investigación es una imagen concreta sobre lo que es el aborto, con una descripción realista y cruda de lo que suponen que sucede con el agente abortado cuando se lleva a cabo el procedimiento, señalando que ocurre desmembramiento, desintegración y aparece una importante presencia de sangre. Estas imágenes coinciden con las presentadas en las campañas de los grupos conservadores antiaborto, lo que indica que dicha propaganda ha tenido mayor penetración en los esquemas representacionales de este grupo.

Una de las funciones de las representaciones sociales corresponde a formar actitudes (Moscovici, 1961), y es evidente que el aborto se encuentra fuertemente asociado a un tono negativo. Para las participantes el aborto es cuestionable, y solo se acepta bajo ciertas condiciones, las que además suponen carencia de agencia por parte de las mujeres. Un poco más sutilmente, es posible señalar que las opiniones valóricas de estas mujeres se encuentran divididas entre una minoría que aboga por la libertad de decisión de 
la mujer y quienes están en desacuerdo condicionalmente con el aborto, vale decir, las participantes lo consideran valóricamente negativo, pero justificado en casos de escasa esperanza de vida del bebé y/o cuando las mujeres no tienen otra alternativa. En relación con lo anterior, la figura de la mujer se encuentra polarizada, siendo presentada en un rol de víctima o de victimaria: es víctima cuando las situaciones contextuales o personales son complejas, y por tanto, es justificado y entendido que aborte, pero es victimaria cuando teniendo circunstancias favorables decide abortar y por ende, atentar contra la vida de un inocente.

A partir de lo anterior, podemos señalar que las ideas ligadas a la libertad de decisión se encuentran en la periferia de la representación, lo que provoca que dicha representación sea más permeable al contexto. Se observa deseabilidad social en algunas respuestas (Davison, 1983), es decir, las mujeres abogan por la libertad de decisión sobre sus cuerpos, pero cuando se les consulta directamente sobre el tema, tienen una opinión negativa del aborto, ya que tiene mayor fuerza el componente hegemónico que el emancipado. La idea del aborto como muerte o asesinato se ubica más centralmente en la representación (Moscovici, 1961), puesto que presenta mayor intensidad de aparición y mayor peso simbólico, además de ser estable.

Adicionalmente, es posible apreciar en lo expresado por las participantes de la investigación la presencia de negaciones, las cuales equivalen al efecto de tercera persona (Davison, 1983). Lo anterior se refleja en frases como: "Cada uno tiene derecho a ver lo que decide hacer, esto no se trata de valores". Estas ideas modulan la representación social del aborto, ya que incluyen los valores de forma latente, en otras palabras, las participantes no lo mencionan de forma explícita, pero sí integran elementos que se pueden considerar afectivos: tienden a darle una connotación afectiva al aborto, por más que hablen de él de manera distanciada y supuestamente "objetiva", lo cual parece asociarse con los discursos de los grupos minoritarios sobre el aborto, quienes difunden un discurso más intelectual. Igualmente, la gran penetración de imágenes "crudas" en la representación del aborto nos hace pensar que las estrategias visuales y concretas llevadas a cabo por los grupos 
conservadores tienen mayor pregnancia que las estrategias más abstractas basadas en derechos llevadas a cabo por los grupos de orientación liberal (Jodelet, 1986).

Es importante mencionar que el discurso respecto al aborto manifestado por los medios de comunicación de masas ha sufrido transformaciones a lo largo de los años. Desde que fue prohibido en el periodo de dictadura desde 1989 hasta la actualidad, el discurso ha pasado por una transición que va desde la oposición total hacia al tema a la incorporación de la idea del aborto bajo las tres causales, siendo actualmente esta forma de pensamiento la imperante (Centro de Estudios Públicos, 2014). Considerando que lo expresado a través de los medios de comunicación se encuentra más o menos influenciado por grupos de poder, los grupos que tienen (más o menos) poder son capaces de controlar mediante el discurso (en mayor o menor medida), en su propio interés, los actos y las mentes de los miembros de otros grupos (Van Dijk, 1999), sirviendo así a la reproducción de determinadas formas de ser, en este caso, respecto al aborto.

Los cambios en el debate público se ven reflejados en la manera en que el aborto es representado, ya que si bien la imagen es mayoritariamente hegemónica, aparecen ideas emancipadas, dando al aborto el carácter de representación polémica. Esto es importante, por cuanto permite pensar la posibilidad de cambios en las concepciones sociales de aborto, de que medie mayor debate social y mayor diversidad de ideas en ese debate.

La mayoría de lo que ocurre en torno a la representación social de aborto es sobre el cuerpo, especialmente sobre el cuerpo del "feto/bebé". En esta línea, como "salida" a la polarización producida, creemos que esta tal vez pasaría por desnaturalizar la imagen del "feto/bebé" y de los niños, de cara a favorecer el cambio de esta forma tradicional de concebirlo, modificándose así el significado que se construye sobre estos participantes. Para ello nos parece importante que el Estado prescinda de intervenir en defensa de posturas respaldadas por orientaciones religiosas y/o políticas, y que gobierne para una sociedad heterogénea que presenta necesidades urgentes, incorporando contenidos representacionales emancipados y polémicos sobre el aborto, y así 
las mujeres no sigan marginadas en la capacidad de tomar decisiones sobre sus propias vidas y su propio su cuerpo.

Finalmente, la predominancia de representaciones hegemónicas en las mujeres participantes, a pesar de su edad y grado de educación, parece mostrar que son los discursos hegemónicos contrarios a la despenalización del aborto los que han permeado más fuertemente el imaginario público sobre el tema. La escasa penetración de ideas sobre los derechos de las mujeres y la apropiación del cuerpo por parte estas, muestra además que los movimientos feministas y progresistas tienen una tarea pendiente respecto de la diseminación de sus posturas sobre la despenalización del aborto en Chile.

\section{Referencias Bibliográficas}

Abric, J. (1993). Central system, peripheral system: Their functions and roles in the dynamics of social representations. Papers on Social Representations Textes sur les Représentations Sociales. $\mathrm{N}^{\circ} 2$.

Abric, J. (1994). Prácticas sociales y representaciones. México: Ediciones Covoacén, S. A. de C, V.

Aguirre, E. (2004). Representaciones sociales y análisis del comportamiento social. En Aguirre Eduardo y Yáñez, Jaime. Diálogos 3. Discusiones en la Psicología contemporánea. Bogotá: Universidad Nacional de Colombia.

Alarcón, M. (2015). Patrones valorativos de actitud en anotaciones en el libro de clases: juicios, afectos y apreciaciones de los docentes en un contexto educativo. Literatura y Lingüística $\mathrm{N}^{\circ} 31$.

Araya, S. (2002) Las Representaciones Sociales: ejes teóricos para su discusión. Cuaderno de Ciencias Sociales № 127. Costa Rica: FLACSO.

Banchs, M. (2000). Aproximaciones Procesuales y Estructurales al estudio de las Representaciones Sociales. Papers on Social Representations $\mathrm{N}^{\circ} 9$.

Besio, M., Chomalí, F. y Neira, J. (2008). Aborto "terapéutico": Consideraciones médicas, éticas y jurídicas. Santiago, Chile: Pontificia Universidad Católica de Chile.

Blazquez, N., Flores, F. y Ríos, M. (2012). Investigación Feminista: epistemología, metodología y representaciones sociales. México: Debate y Reflexión.

Breakwell, G. (2001). Social representational constraints upon identity processes. En Representations of the social: Bridging Theoretical Traditions. Oxford: Blackwell.

Colectiva Feminista Libertaria "Histeria Colectiva" (2014). Declaración Pública Histeria Colectiva 25 de Julio 2014. Santiago: Chile. 
Colegio de Matronas y Matrones de Chile (2014). Colegio de Matronas y Matrones de Chile pide debatir tema del aborto en serio y considerar las determinantes sociales. Santiago: Chile.

Corporación Humanas (2005): Encuesta Nacional de Opinión Percepción política e implicancias electorales de las mujeres inscritas en los registros electorales Chile, mayo-junio de 2005.

Centro de Estudios Públicos (2014). Extraído desde http://web.vrserver2.cl/cepchile/encuestaCEP_Julio2014.pdf

Centro Legal para Derechos Reproductivos y Políticas Públicas, (1998). Encarceladas: leyes contra el aborto en Chile; un análisis desde los derechos humanos. Chile: Foro Abierto de Salud y Derechos Reproductivos.

Código Penal, Chile. Artículo 342 al 345, 12 de noviembre de 1874.

Davison, Phillips (1983). The third-person effect in communication. Public Opinion Quarterly $N^{\circ} 47$.

Dides, C., Benavente, C. y Sáez, I. (2011). Dinámicas políticas sobre aborto en Latinoamérica: estudio de casos. Santiago, Chile: Flacso.

Facio, A. y Fríes, L. (2005). Feminismo, género y patriarcado. Revista sobre enseñanza del Derecho de Buenos Aires $N^{\circ} 6$.

Figueroa, M. (2014). Representaciones sociales del futuro en el arte. URBS. Revista de Estudios Urbanos y Ciencias Sociales. 2(2), 103-116.

Flores, F. (2003). Psicología social y género. El sexo como objeto de representación social. México: McGraw Hill.

Jodelet, D. (1986): La representación social: fenómenos, conceptos y teoría. En: Moscovici, Serge. Psicología social II. Pensamiento y vida social. Psicología social y problemas sociales. Barcelona: Paidós.

Kaplan, N. (2004). Nuevos desarrollos en el estudio de la evaluación en el lenguaje: la teoría de la valoración. Boletín de Lingüística. 22, 52-78.

Martin, J. y White, P. (2005). The language of evaluation: Appraisal in English. Hampshire: Palgrave Macmillan.

Moscovici, S. y Lage, E. (1976). Studies in social influence III: Majority versus minority influence in a group. European Journal of Social Psychology $N^{\circ} 6$.

Moscovici, S. (1979). El psicoanálisis, su imagen y su público. Buenos Aires: Editorial Huemul.

Moscovici, S. (1988). Notes towards a description of social representations. European Journal of Social Psychology. $\mathrm{N}^{\circ} 3$.

Rodríguez, T. y García, M. (2007). Representaciones sociales. Teoría e investigación. México: Editorial CUCSH-UDG.

Sandoval, C. (1997). Sueños y sudores en la vida cotidiana de trabajadores y trabajadoras de la maquila y la construcción. Costa Rica: Editorial de la Universidad de Costa Rica. 
Scott, J. (1996). El género: Una categoría útil para el análisis histórico. En Lamas, Marta. El género: la construcción cultural de la diferencia sexual. México: PUEG.

Schongut, N. (2012). La construcción social de la masculinidad: poder, hegemonía y violencia. Psicología, conocimiento y sociedad $\mathrm{N}^{\circ} 2$.

Spink, M. (1994). Desvendando as teorias implicitas: uma metodologia de análise das Representaçoes Sociais. En: Jovchelovitch, Sandra y Guareschi, Pedrinho (Orgs) Textos em Representaçoes Sociais. Petrópolis: Vozes.

West, C. y Zimmerman, D. (1999). Haciendo género. En: Navarro, M. y Stimpson, C. (comps.). Sexualidad, género y roles sexuales. Argentina: Fondo de Cultura Económica.

Van Dijk, T. (1999). Ideología, una aproximación multidisciplinaria. Barcelona: Gedisa.

\section{Para citar este artículo:}

Jara, L., Rojas, C. y Martínez, S. (2017). Mujeres jóvenes y el aborto en Chile: representaciones polarizadas. Collectivus, Revista de Ciencias Sociales, 4(1), 41-66.

Doi: http://dx.doi.org/10.15648/Coll.1.2017.3 